MedieKultur | Journal of media and communication research | ISSN 1901-9726

Article - Theme section

\title{
Structure, complexity and cooperation in parallel external chat interactions
}

\section{Anette Grønning}

MedieKultur 2012, 53, 57-81

Published by SMID | Society of Media researchers In Denmark | www.smid.dk The online version of this text can be found open access at www.mediekultur.dk

This article examines structure, complexity and cooperation in external chat interactions at the workplace in which one of the participants is taking part in multiple parallel conversations. The investigation is based on an analysis of nine chat interactions in a work-related context, with particular focus on the content of the parallel time spans of the chat interactions. The analysis was inspired by applied conversation analysis (CA). The empirical material has been placed at my disposal by Kristelig Fagbevegelse (Krifa), which is Denmark's third-largest trade union. The article's overall focus is on "turn-taking organisation as the fundamental and generic aspect of interaction organisation" (Drew \& Heritage, 1992, p. 25), including the use of turn-taking rules, adjacency pairs, and the importance of pauses. Even though the employee and the union members do not know one another and cannot see, hear, or touch one another, it is possible to detect an informal, pleasant tone in their interactions. This challenges the basically asymmetrical relationship between employee and customer, and one can sense a further level of asymmetry. In terms of medium, chat interactions exist via various references to other media, including telephone calls and e-mails. 


\section{Introduction}

Since the turn of the millennium, chat interactions have developed from being the preserve of the private sphere to becoming one of the preferred informal forms of communication among particular groups (teenagers, dating services for singles, etc.) and being used internally and externally in work-related contexts at both private companies and public organisations. Highly diverse sectors within both the private and public work sphere as well as highly diverse branches of industry (for instance, furniture and education) with highly diverse product types of both a tangible and intangible nature have begun offering their target groups (customers, members, students, etc.) the possibility of a chat service to supplement in-person conversations, e-mails and telephone calls. Apart from a desire to meet customers where they are, there are two specific advantages to introducing chat sessions. Firstly, the individual employee can deal with several interactions at the same time (typically three to five), and secondly, chats can potentially reduce the number of e-mails and the waiting time occasioned by telephone congestion. A company may choose, for example, to shut down e-mails during working hours, which results in an upgrading of telephone and chat interactions (Grønning, 2010).

Chat interactions between customers and employees differ from the more established private forms of chat, that is, those used for informal chatting and socialising, planning of events, and cooperation among school students (Lenhart et al., 2001). This means that - as is the case with private versus institutional oral conversations (Drew \& Heritage, 1992) there is an expectation that institutional, external chats will be characterised by a higher level of actual problem solving since most of the individual chat approaches have a clearer objective than general private chat interactions, the intention of which are mainly getting to know one another (teenagers for social chatting, singles for dating, etc.). The customer communicates because he or she wishes to receive an answer or assistance in solving a particular problem. At the same time, there are a number of other implicit demands on the part of the company/organisation (for instance, regarding time consumption and content) that are absent in the case of private chatting. We are thus looking at a new type of online interaction in an institutional context. This is an interaction in which it has become evident that at least one of the parties is often interacting with a number of other parties simultaneously (Grønning, 2010).

Apart from the number of ongoing interactions, there is, at a more basic level, an asymmetrical relationship between employee and customer, one in which the employee assumes the role of expert and the customer assumes the role of non-expert (layman). As Drew \& Heritage (1992, p. 47) formulate it:

A central theme in research on institutional interaction is that in contrast to the symmetrical relationships between speakers in ordinary conversation, institutional interactions are characteristically asymmetrical. 
According to Drew \& Heritage, this can, for example, be seen in the form of a predominant question-and-answer pattern caused by the different levels of knowledge and power and in the form of differing conceptions of routine issues.

Until now, Danish research into external chat interactions has focused exclusively on the one-to-one aspect, i.e. on analysing how an individual chat interaction takes place between a single employee and a single customer. The research has not considered cases in which the employee chats with several customers simultaneously (many one-to-one interactions). See, for example, Grønning (2010) for case studies of the IKEA Furniture Group and the Studievalg Fyns Chatservice [Study Choice Fyn Chat Service] advisory unit, which are targeted at customers and students respectively. At the same time, the broader research into chatting features a fundamental discussion about the extent to which it is difficult to take part in numerous chat interactions simultaneously. Several studies of group interactions (many-to-many) deal with this issue (O’Neill \& Martin, 2003; Smith, Cadiz, \& Burkhalter, 2000; Viegas \& Donath, 1999), while others feel that this issue has been blown out of proportion (Herring, 1996). Because of this, the present article examines structure, complexity and cooperation in parallel chat interactions in the workplace. The investigation is based on an analysis of nine chat interactions in a work-related context, with particular focus on the content of the parallel time spans of the chat interactions. The analysis was inspired by applied conversation analysis (CA). The parallel time span is to be understood as the point in time when at least one of the participants is taking part in several interactions. The article's overall focus is the organisation of turn-taking, including the use of turn-taking rules, adjacency pairs, and the importance of pauses.

The article is structured as follows: Prior to the analysis of the chat interactions there is a section on turn-taking in oral conversation, followed by a section on turn-taking in chat interactions, since the latter is regarded as a variant of the former (O'Neill \& Martin, 2003, with reference to Garcia \& Jacobs, 1999). The analysis is divided into two groups (Cluster 1 and Cluster 2), with a brief introduction to context, the actual interaction extract, and a detailed interaction analysis as well as a diagrammatic representation of the parallel interactions. The conclusion contains a summary of the most important analytical points relative to structure, complexity and cooperation as well as a short comment on the asymmetrical aspect of such interactions. The perspective is broadened to e-mails and telephone conversations.

\section{Turn-taking in oral conversation}

To understand turn-taking in chat interactions, we must first examine the phenomenon in oral conversation. It is possible to use applied CA of institutional oral conversations to clarify how institutional interactions are organised and constituted through language (Nielsen \& Nielsen, 2005; Asmuss \& Steensig, 2003). Applied CA is understood as meaning: 
[...] analysis of interactions that use the conversation-analytical method, and that can form the point of departure for improving communication in professional contexts. (Asmuss \& Steensig, 2003, p. 20).

Both nationally and internationally, research is being undertaken concerning institutional interactions, i.e. face-to-face conversations and telephone conversations in the workplace. Nielsen, Steensig \& Wagner (2006) describe current major Danish and international projects analysing such interactions. Regarding American and British studies, it is, for example, emphasised that researchers initially analysed conversations from everyday life. This changed in 1992, when Drew \& Heritage, in their book Talk at Work, came to grips with institutional interactions, particularly focusing on interactions in the health service sector, courts, schools, the media, and high-tech contexts. This is how Drew \& Heritage (1992, p. 59) describe their focus:

[...] we here restrict the term institutional interaction to interactions that are work- or taskoriented and 'non-conversational' [...]. Our use of the term does not extend to persons who engage in mundane conversation about everyday topics while they happen to be working, for example, on an assembly line or in a food-processing outlet.

In oral conversation, turn-taking behaviour is overwhelmingly characterised by one person talking at a time, even if the number and length of turns varies (Sacks, Schegloff \& Jefferson, 1974). . The places where a new speaker gets a chance to speak are termed Transition Relevance Places (TRPs). Turn-taking is coordinated at such places, and a change of speaker can take place in the following ways (model from Sacks, Schegloff \& Jefferson, 1974):

1a) By the person speaking indicating the next speaker

1b) By the next speaker simply taking over

1c) If neither of these activities takes place at the TRP, the present speaker can continue speaking.

2) If neither $1 \mathrm{a}$ nor $1 \mathrm{~b}$ have taken place, but the present speaker is still speaking as a result of $1 c$, the 1a-1c set of rules comes into force again at the next TRP, etc.

Nielsen \& Nielsen (2005, p. 37) refer to Rule 2 as "and so on and so forth". We are thus looking at two basic rules, one of which has three sub-rules.

It is emphasised that all " [...] turns normally have a tripartite structure consisting of:

The relation to the previous turn

The project for the present turn

The relation to the following turn".

Nielsen \& Nielsen (2005, p. 38). 
In oral conversation, turns are constructed as described with the aid of turn units made up of words, expressions, phrases or whole sentences (Sacks, Schegloff \& Jefferson, 1974). The conclusion of each turn unit thus constitutes a TRP since the participant in the conversation can hear the utterance that is being developed and at the same time prepare his or her own next turn unit. With regard to the importance of pauses, the person speaking can use pauses strategically, for instance by placing a pause in the middle of a turn unit instead of at the end or by using other techniques such as hurrying from one turn unit to the next in order to prevent the next potential speaker from conceiving of the possibly ended turn unit as a TRP. As far as the rules for turn-taking in oral conversation are concerned, it has been emphasised that "each turn" is constructed according to a 'receiver design', i.e. that down to the smallest unit it is constructed on the basis of who is going to receive it." (Nielsen \& Nielsen, 2005, p. 37).

An important content-related element in oral conversation is the presence of so-called adjacency pairs (Sacks, Schegloff \& Jefferson, 1974), also known as proximity pairs (Asmuss $\&$ Steensig, 2003). The first part of an adjacency pair makes certain particular action requests regarding the next utterance, that is, the second part of the adjacency pair. The adjacency pair can, for example, consist of question-answer or of greeting-greeting (Steensig, 2001).

This knowledge is now used to compare turn-taking in oral conversation with turntaking in chat interactions.

\section{Turn-taking in chat interactions}

The concept of chatting or instant messaging is variously defined in the literature. This investigation uses the definition by Grinter \& Palen (2002, p. 21) as its starting point:

Internet-based synchronous text chat, with point-to-point communication between users on the same system. A window is dedicated to the conversation with messages scrolling upward and eventually out of view as the conversation ensues.

Compared with oral conversation, chat interaction is primarily characterised by the fact that the participants read one another's turns rather than listen to them. Furthermore, the participants type their own turns rather than speak them. Chat interactions are persistent (as opposed to oral, non-persistent conversations) since participants can, at a minimum, see the most recent section of the chat interaction that is taking place. In addition, a chat interaction is characterised by being quasi-synchronous, which means that it is impossible to speak simultaneously. It is, however, possible to prepare the production of input at the keyboard synchronously, which must be considered to be chat's equivalent of "simultaneous start" (Sacks, Schegloff \& Jefferson, 1974). In some chat systems, both participants can see whether the other participant is typing (for instance, if a small pen appears in the chat window), although one cannot see the content being typed.

Turn allocation (the same as allocating speaking terms; Nielsen \& Nielsen, 2005, p. 34) in a chat interaction does thus not take place in the same way as in an oral conversation 
since the participants do not allocate speaking turns but instead type contributions into the chat system. Chat interactions possess, moreover, the distinctive feature of participants being unable to count on their own contributions being placed in the chat following any other particular message (the other participant can enter text first). The parties involved thus cannot know in advance precisely where their contributions will be posted, meaning that turn-taking to a greater extent involves posting a future message rather than posting the next message (Garcia \& Jacobs, 1999). In a chat interaction with several participants, this can lead to problems for those taking part since it can be difficult to gain an overview of the many different strands of the conversation going on simultaneously. A number of studies address this issue (O'Neill \& Martin, 2003; Smith, Cadiz, \& Burkhalter, 2000; Viegas \& Donath, 1999), which can lead to a preference for short turns (Smith, Cadiz, \& Burkhalter, 2000).

Some studies highlight that turn-taking in a chat interaction is a variant of that in oral conversation (O’Neill \& Martin, 2003, with a reference to Garcia \& Jacobs, 1999). Turn-taking in a chat interaction does, however, differ substantially from that in oral conversation on three points: 1) The presence and importance of TRPs, 2) Self-repair of messages being prepared, and 3) The importance of pauses (Garcia \& Jacobs, 1999). For the present purposes, I will omit Point 2 since the present research does not have access to data on this subject (Garcia and Jacobs made use of video recordings).

With regards to Point 1 on the presence and meaning of TRPs, turn construction in a chat interaction is only possible for the individual participant producing a turn unit, making it impossible for those taking part in the interaction to hear or anticipate TRPs. Even though the TRP concept itself is thus challenged in a chat context relative to in oral conversation, the participants typically treat a finished message as a TRP since they typically start typing their next contribution upon receiving a message (Garcia \& Jacobs, 1999). With regards to Point 3 on the meaning of pauses, the chat participant, like a participant in an oral conversation, has the possibility of placing pauses in a turn. These pauses do not, however, have the same effect on the actions of other participants as is the case in oral conversation. During a silent period, participants in a chat interaction can exclusively sense the silent participant as typing, editing, reading, or waiting. For this reason, pauses in a chat interaction do not create the same potential place for handing over a turn as they do in oral conversation, apart from the fact that every delay makes it more likely that the other participant will post his or her message first. Pauses in chat interactions can therefore exclusively be used to strategically delay one's own contribution (Garcia \& Jacobs, 1999).

One special element in chat interactions is the absence of synchronous feedback signals. Chats often require meta-communication and the verbalisation of what is taking place between problem-solving turns through the use of utterances such as "I'll just check it out," "Just a moment," and " 2 secs" (Grønning, 2010). Similarly, chat sessions with several participants may include icons. The most common of these are smileys or emoticons, but there are also examples of small image smileys and figures, for instance waving hands (Hougaard, 2004). 
Two elements from studies of group chat interactions (many-to-many) here in order to investigate the extent to which it is relevant for the study in a Krifa context. These are 1) multiple turns, and 2) phantom adjacency turns. It has been demonstrated that, in group chat interactions, the sequential relationship between turns is maintained through the use of multiple turns. There are often several turns "on-top-of-each-other" representing a single answer (Isaacs et al., 2002; Garcia \& Jacobs, 1999). Participants can also attempt to regain their turn by coming up with a quick comment (O'Neill \& Martin, 2003). When many participants contribute to a chat interaction (many-to-many), phantom adjacency pairs may arise. This is a term for the adjacency pairs in which the second part of the pair is made explicit prior to the first part of the pair (Garcia \& Jacobs, 1999). This takes place because posting is not synchronous and because the individual chat participant cannot personally control the order of contributions.

The following is therefore included in the analysis of the institutional chat interaction: At a general, top level, there are a number of similarities and differences between oral conversation and chat interaction. When it comes to turn-taking and content, the pattern of chat interaction is regarded as a variant of that in oral conversation. Individual elements of a sentence or utterance can project the extent to which a turn will be continued. In terms of content, multiple turns, adjacency pairs, and phantom adjacency pairs may well arise. Certain studies point out that it can be difficult to take part in several interactions simultaneously since this can lead to interactional incoherence, while others are of the opinion that this problem has been exaggerated (Herring, 1996). It is not possible to provide feedback signals during chat interaction, and new means of compensating for this have sprung up, for example, finding words for the silence between the problem-solving turns and using icons such as smileys.

\section{Analysis}

In order to investigate the structure of institutional chat interactions in which at least one of the parties is taking part in several parallel interactions, this analysis will seek to answer the following questions: How do the various concrete participation structures enable the implementation of chat interaction between employee and union member? What characterises the content of the parallel portion relative to structure, complexity and cooperation?

The empirical material has been placed at my disposal by Kristelig Fagbevægelse (Krifa), which is Denmark's third-largest trade union, with 190,000 members. The material comprises a total of 60 chat interactions between John, a Krifa employee, and various Krifa members. Nine of the 60 interactions have been specifically selected for analysis since these are part of two parallel sequences (clusters) in which the employee takes part in several lengthy parallel chat interactions that show considerable diversity. The members are each involved in a one-to-one chat interaction while the employee seems to be involved in a one-to-many interaction in which he monitors several chat screens, though one could argue that we are, in fact, looking at many one-to-one interactions. We are, then, considering institutional 
chatting between two parties in closed forums even though one of these parties has access to several forums. The nine interactions in two clusters have been selected since they contain the longest-lasting parallel sequences in the data material. Those taking part do not know one another when the interactions begin. All examples are reproduced as closely as possible to the original (Danish) interaction. Typos and misspellings are not translated but marked with [sic]. All personal names are fictitious and other sensitive material has been replaced by " $[\mathrm{x}]$ " or, to increase comprehensibility, by short explanations in square brackets.

Over the course of three weekdays, the employee John takes part in 60 chat interactions. These have the following overall structure: The union member starts by choosing the menu tab "About us" on the union's website and then selects "Contact us" (see Figure 1). The chat function and the presence of an employee photo indicate that the employee is available for chatting and that this is how communication will take place if the member wishes to fulfil his or her goal. The member then clicks the button stating "Chat with us and get an answer now. The chat function is open 8:00-16:00 on all weekdays" (compliance with communication format), after which an automatically generated message pops up, namely, " $\mathrm{Hi}$, welcome to Krifa - how can I help you?" It is then the member's turn to interact. During the interaction, the member can see a small (static) photo of the employee at the other end and can follow his or her own chat interaction with the employee via the chat system. The member cannot, however, see the other interactions in which the employee is taking part.

Figure 1: The union member chat session starts from this section of Krifa's website.

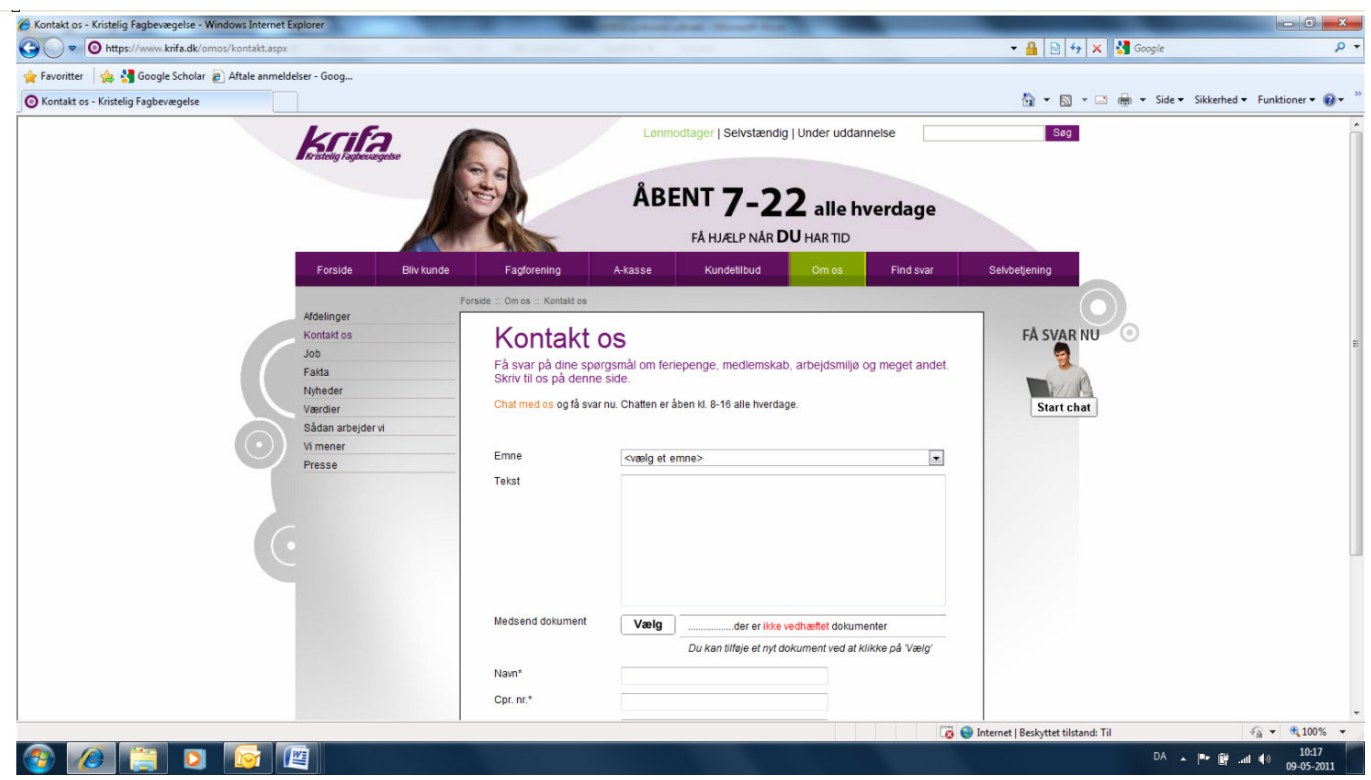

Below, I will first present two clusters on interactions at an overall level focusing on structure and context and then move on to considering them in detail, focusing in particular 
on the parallel time span. In order to save space, only the first interaction of each cluster is shown in its entirety. Only the parallel time span is shown for the other interactions.

\section{Cluster 1: Structure and context}

The first cluster consists of five chat interactions. These take place during the time span of 8:13:26-8:27:28. As evident in Figure 2 the length of these sessions varies from just over five minutes $(5: 10)$ to almost seven minutes (6:56). The interactions overlap, with Numbers 1,2 and 3 being starting atop one another. After 1 and 2 finish, 4 starts up, and after 3 finishes, 5 begins. In the time span 8:17:35-8:20:18 the employee is thus engaged in three interactions simultaneously. In terms of content, the interactions in Cluster 1 deal with questions regarding employee rights when one is given notice while on maternity leave, unemployment benefit, early retirement pension, mileage expenses during job activation, problems with payments from the trade union, and adherence to a job plan.

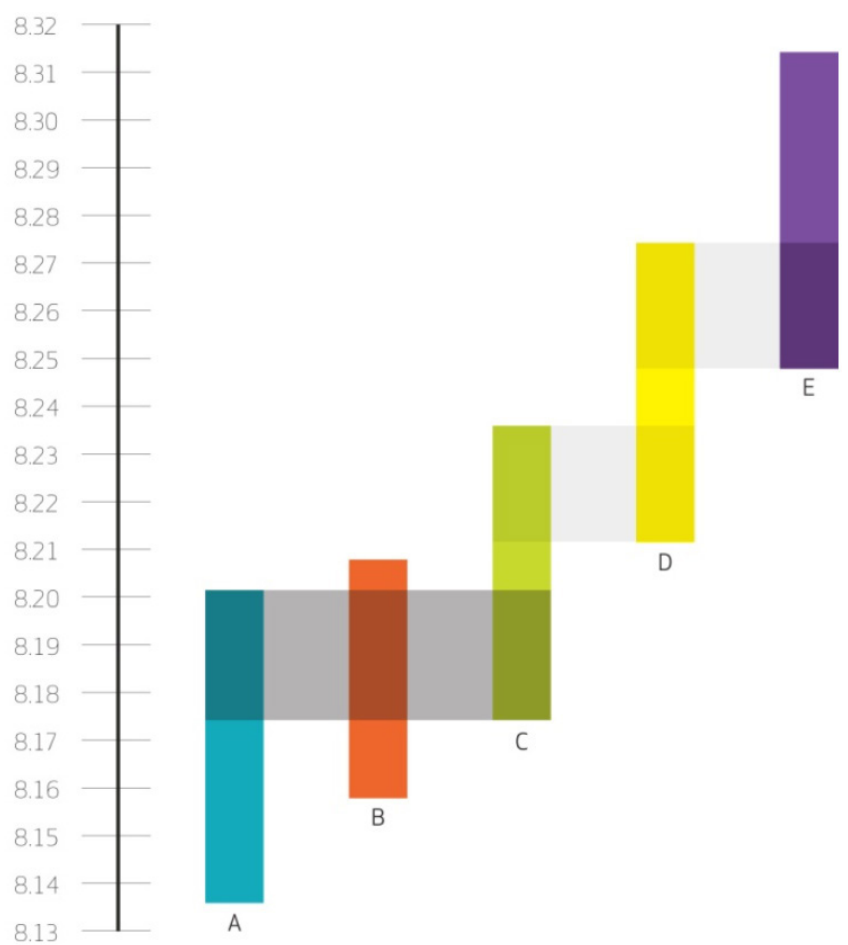

Figure 2: The parallel time span (marked in grey) in Cluster 1.

The first interaction in Cluster 1 (Interaction A) is initiated by a female union member who is on maternity leave. In an attempt to provide as full a context-dependent picture as possible regarding what happens with those taking part up until the parallel time span, Interaction $A$ is reproduced in its entirety. 


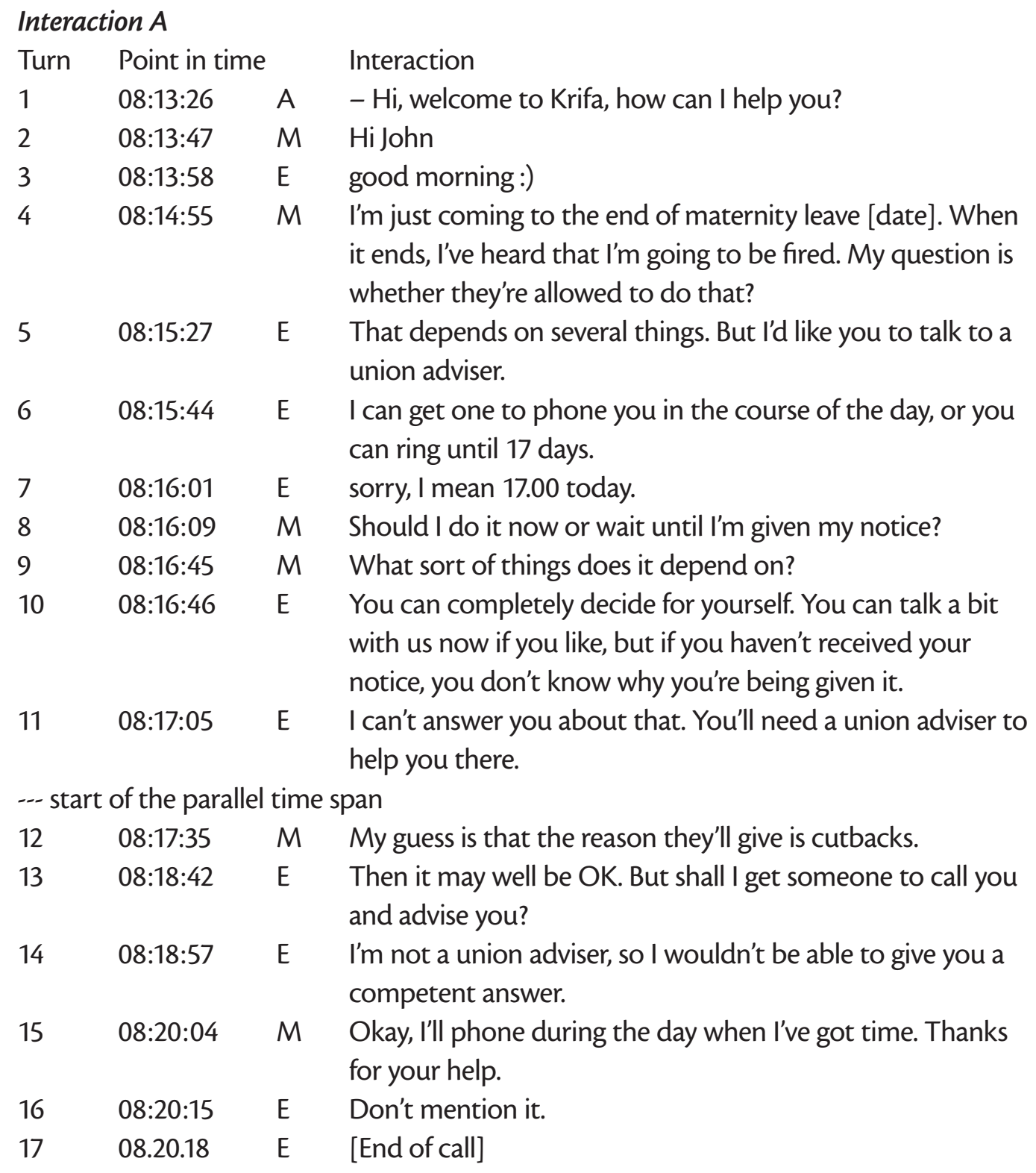

$A$ is automatically generated. $M$ is the trade union member. $E$ is the employee.

With the aid of a personal greeting ("Hi" + employee's first name) the member takes over after this automatically generated opening. The employee answers with a "good morning :)", which can be seen as a minor divergence from the pattern as a "Hi + member's name" is what would be expected. The short multiple turns (E: Turns 5, 6 and 7, M: Turns 8 and 9, and E: Turns 10 and 11) predominate and help the session run smoothly between the participants. Both indicate their presence. If there is a typo, the content is immediately repaired (Turn 7). Even though only two people are taking part and are doing so in a rigid 
framework, one can observe a complex interactional structure. If, for example, one reads the union member's Turn 10 (E) as an answer to Turn $9(M)$, much could be misunderstood. Turn 9 (E) is thus a question directly in extension to the answer in Turn $5(M)$, and Turn 10 (E) is not an answer to Turn 9 (E) but a reply to Turn 8 (E), just as Turn 11 (E) is an answer to Turn $9(M)$ (phantom adjacency pairs). This underlines the experience of posting a future message rather than necessarily posting the next message. Turns $9(M)$ and $10(E)$ take place at an interval of only one second and can thus be seen as the best example in the material of quasi-synchronousness. The frequency change of turns (with, for example, 1, 8 and 11 seconds between them) creates dynamism between the two chatters.

The second interaction (Interaction B) in Cluster 1 concerns the possibility of opting out of an early retirement pension.

When isolated, Interaction B's share of the parallel time span looks like this:

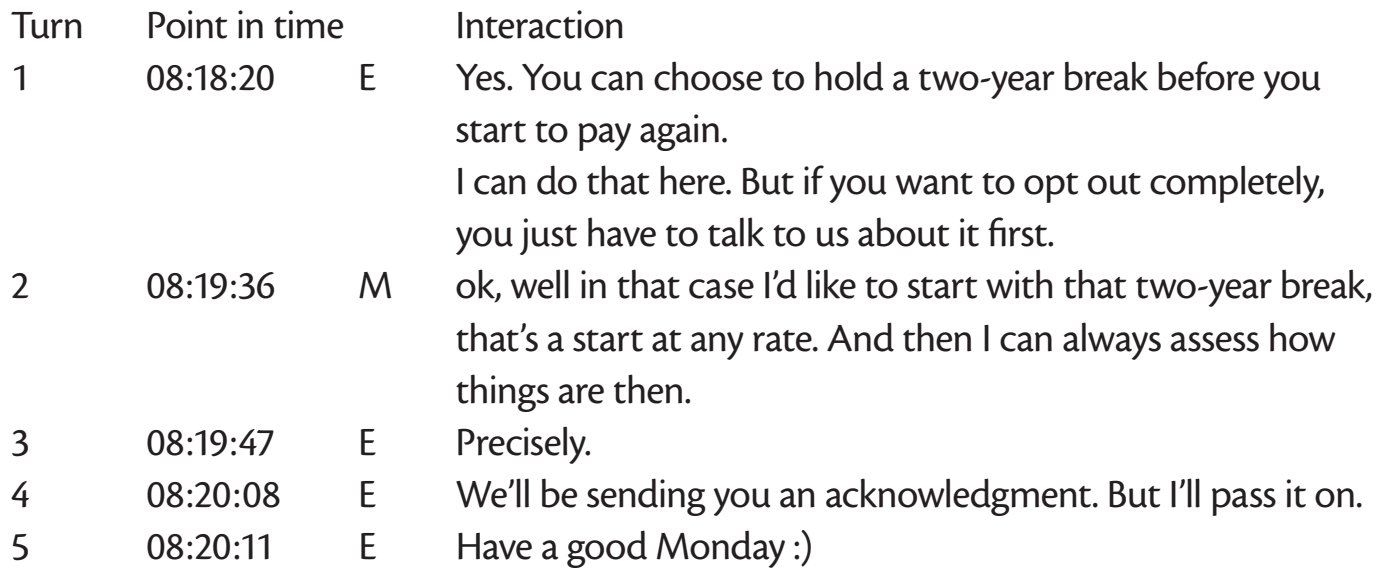

$M$ is the trade union member. $E$ is the employee.

Interaction $B$ has been going on for 1:46 prior to the parallel time span, at which point the employee chooses to be quite direct by answering: "Yes. You can choose to hold [...]" (see the whole contribution above). The concluding words "[...] you just have to talk to us about it first" is the employee's signal of handing over turns. The turn is an answer to the member's initial question. The employee is demonstrating here that he does not perceive the chat interaction as being a chat. After this, the member continues his turn (1c) as in Interaction A and then has three short consecutive multiple turns (Turns 3, 4, and 5).

The third interaction (Interaction C) begins with the parallel time span itself and concerns contact with the trade union. When isolated, Interaction C's share of the parallel time span looks like this: 


\begin{tabular}{|c|c|c|c|}
\hline Turn & Point in time & & Interaction \\
\hline 1 & 08:17:36 & $A$ & - Hi, welcome to Krifa, how can I help you? \\
\hline 2 & 08:20:05 & M & $\begin{array}{l}\text { Hi. I talked to Pia Hansen last Thursday about certain issues } \\
\text { to do with my right to unemployment benefit after my } \\
\text { training's over. She said she'd phone back, but unfortunately } \\
\text { I wasn't able to come to the telephone later that day. I just } \\
\text { wanted to say to her that she can contact me all this week } \\
\text { after } 15.00 \text { and Friday after } 12.00 \text {. }\end{array}$ \\
\hline \multicolumn{4}{|c|}{..- end of the parallel time span } \\
\hline 3 & $08: 21: 40$ & $\mathrm{E}$ & $\begin{array}{l}\text { Thank you. I just need your social security number so I can } \\
\text { pass on your message. }\end{array}$ \\
\hline
\end{tabular}

$A$ is automatically generated. $M$ is the trade union member. $E$ is the employee.

Interaction $\mathrm{C}$ is initiated during the parallel time span by the member who, following the automatically generated welcome turn, chats the longest turn content of the entire cluster: "Hi. I talked to [...]" (see the whole contribution above). The appearance of the adjacency pair " $\mathrm{Hi}-\mathrm{Hi}$ " is thus for the first participant system-generated and for the second participant personally generated. Just as in Interaction B, the employee does not use an introductory form of address and is direct in his reply. This turn, however, lies outside the parallel time span, since, as shown, there is a pause of almost two minutes between Turn 2 and Turn 3 before the employee returns to Interaction $C$.

Compared with Interactions A and B, the employee is not active in taking turns in Interaction C. The system contributes exclusively (on behalf of the employee) with the automatically generated welcome turn. This may indicate that it is difficult to take equal part in three simultaneous chat interactions.

\section{Cluster 1: Summary}

The following is characteristic of turn-taking during the parallel time span in this cluster:

- The member takes a turn (turn-taking Rule $1 \mathrm{~b}$ ) in order to agree, express a wish, or express thanks.

- The employee answers in the affirmative, comments, and continues his turn, especially when it comes to multiple turns (turn-taking Rule 1c).

- The turn-taking frequency ranges from one second to 2:29. The employee pauses when he refers to a union adviser (A, Turns 1,2 and 3), and the member does so at the beginning of the interaction (C, Turns 1 and 2 ).

There are adjacency pairs, both automatically and personally generated. There are no phantom adjacency pairs during the parallel time span. 
Article: Structure, complexity and cooperation in parallel external chat interactions

The combined parallel interaction pattern in Cluster 1 looks as follows. (This is my construction, to clarify the sequence of turns. It does not appear this way to the employee):

\begin{tabular}{|c|c|c|c|}
\hline Turn & Point in time & & Interaction \\
\hline $1(\mathrm{~A} 1)$ & 08:17:35 & $M$ & My guess is that the reason they'll give is cutbacks. \\
\hline $2(\mathrm{C} 1)$ & 08:17:36 & $\mathrm{E}$ & - Hi, welcome to Krifa, how can I help you? \\
\hline 3 (B1) & 08:18:20 & $\mathrm{E}$ & $\begin{array}{l}\text { Yes. You can choose to hold a two-year break before you } \\
\text { start to pay again. I can do that here. But if you want to opt } \\
\text { out completely, you just have to talk to us about it first. }\end{array}$ \\
\hline $4(\mathrm{~A} 2)$ & 08:18:42 & $\mathrm{E}$ & $\begin{array}{l}\text { Then it may well be OK. But shall I get someone to call you } \\
\text { and advise you? }\end{array}$ \\
\hline $5(\mathrm{~A} 3)$ & 08:18:57 & $\mathrm{E}$ & $\begin{array}{l}\text { I'm not a union adviser, so I wouldn't be able to give you a } \\
\text { competent answer. }\end{array}$ \\
\hline $6(\mathrm{~B} 2)$ & 08:19:36 & $M$ & $\begin{array}{l}\text { ok, well in that case l'd like to start with that two-year break, } \\
\text { that's a start at any rate. And then I can always assess how } \\
\text { things are then. }\end{array}$ \\
\hline $7(\mathrm{~B} 3)$ & 08:19:47 & $\mathrm{E}$ & Precisely. \\
\hline $8(\mathrm{~A} 4)$ & 08:20:04 & $M$ & $\begin{array}{l}\text { Okay, I'll phone during the day when l've got time. Thanks } \\
\text { for your help. }\end{array}$ \\
\hline $9(\mathrm{C} 2)$ & 08:20:05 & $M$ & $\begin{array}{l}\text { Hi. I talked to Pia Hansen last Thursday about certain issues } \\
\text { to do with my right to unemployment benefit after my } \\
\text { training's over. She said she'd phone back, but unfortunately } \\
\text { I wasn't able to come to the telephone later that day. I just } \\
\text { wanted to say to her that she can contact me all this week } \\
\text { after } 15.00 \text { and Friday after } 12.00 \text {. }\end{array}$ \\
\hline 10 (B4) & 08:20:08 & $\mathrm{E}$ & We'll be sending you an acknowledgment. But l'll pass it on. \\
\hline $11(B 5)$ & 08:20:11 & $\mathrm{E}$ & Have a good Monday:). \\
\hline $12(\mathrm{~A} 5)$ & 08:20:15 & $\mathrm{E}$ & Don't mention it. \\
\hline $13(\mathrm{~A} 6)$ & 08.20 .18 & $\mathrm{E}$ & [End of call] \\
\hline
\end{tabular}

Figure 3: Cluster 1 - the parallel time span (from the employee's perspective).

$M$ is the trade union member. $E$ is the employee.

Red $=$ Interaction A

Green = Interaction B

Blue $=$ Interaction C

The parallel time span (Figure 3) lasts 2:42 and contains three interactions consisting of 13 speaking turns (the individual interactions last from two to six turns). As can be seen, the employee shifts between three interactions in Turns 2, 3 and 4. In Turns 7, 10 and 11, the employee takes part in a single interaction and only subsequently changes to another inter- 
action in Turn 12. In this time span, it could become especially complicated for the employee to keep track of the many elements of conversation since the individual relationships to the preceding turn potentially lead to one of four chat interactions taking place - refer to the relationship to the preceding turn, the project for the turn itself, and the relationship to the subsequent turn (Nielsen \& Nielsen, 2005). However, no explicit problems of understanding arise. In Turns 4 and 5 and Turns 10 and 11, the employee - as described - takes two consecutive turns. These do not represent turn-taker shifts but merely turn shifts. Only in Turn 7 are we dealing with a turn-taker shift, where the relationship to the previous interaction refers to the same local chat interaction: Here, the employee answers "Precisely" following the union member's turn.

It becomes clearer within the overall interaction pattern why the employee does not press for content in Interaction C. My proposed explanation is that the employee is simply too busy with Interactions A and B. After the automatically generated turn (Turn 2), the union member takes over personally (Turn 9), but nothing further takes place in Interaction $\mathrm{C}$ during the parallel time span. The employee focuses both on the preceding turn of the individual chat interaction and on the subsequent/future turn since he chooses several times to contribute with consecutive turns in the same interaction (Interactions A and B) but also chooses not to take part (Interaction C).

Despite the three parallel chat interactions taking place, the employee has enough energy in reserve to be able to conclude Interaction B with "Have a good Monday:)" (Turn 11) four seconds before he concludes Interaction A with "Don't mention it" (Turn 12). Seven seconds prior to concluding Interaction A, he chats in Interaction B "We'll be sending you an acknowledgment. But l'll pass it on." (Turn 10).

The employee spends the longest time (= pause) to supply the turn units in cases of a reference to a more complex future sequence. This results in a 44-second break between the employee's Turns 2 and 3 during the parallel time span. It is here that the employee emphasises to the union member that "[...] if you want to opt out completely, you have to talk to us about it first." The employee spends the least time in supplying the turn units that are part of an adjacency pair, such as "Have a good Monday :)" (Turn 11) and "Don't mention it" (Turn 12), where the interval between the turns (the pauses) reach as little as three and four seconds respectively.

When it comes to projection, it is particularly questions during the parallel time span in Cluster 1 that signal turn take-over from one participant to the other, such as in Turns 1, 2 and 4. The employee chooses to use a single smiley in Turn 11 as part of the wish "Have a good Monday :)". None of the three union members use icons.

The basic understanding is that the employee is the expert who the customers access. The asymmetrical relationship between employee and union member is further reflected in the number of turns. The employee takes 9 of the 13 turns, despite the fact that he is taking part in three parallel interactions. His turns, however, are shorter than those of the union members. Similarly, he shows a strong tendency to use multiple turns. Even though 
the employee and the members do not know one another and cannot see, hear, or touch each other, one can notice a warm, pleasant tone in some of their utterances. Examples from the employee such as "you just have to talk," "Then it may well be OK," "Precisely," "You'll be hearing from us," "Have a good Monday:)," and "Don't mention it" as well as from the members such as "ok, well in that case l'd like to,", "that's a start at any rate," "and then I can always," "Okay, I'll phone," "Thanks for your help," and "I'd just like to say" paint a picture of an informal conversation in which all those involved feel at ease. These are no signs of misunderstandings, which might have arisen from the number of interactions in which the employee is taking part. There are no explicit reactions to pauses.

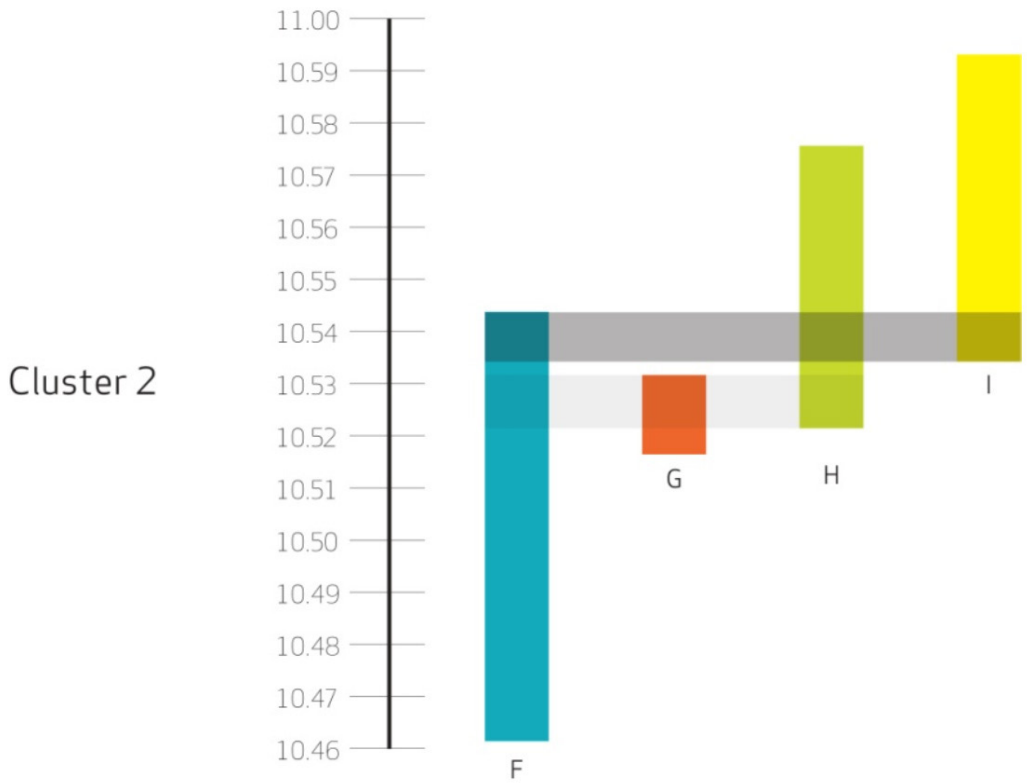

Figure 4: The parallel time span (marked in grey) in Cluster 2.

\section{Cluster 2: Structure and context}

The second cluster consists of four chat interactions. These take place during the time span of 10:46:10-10:59:18. The length of the sessions varies from 1:32 to 8:12 minutes. The interactions overlap, with Interactions 2, 3 and 4 starting while Interaction 1 is still taking place. By the time Interaction 4 starts, Interaction 2 is finished, but Interactions 1 and 3 are still taking place. Interaction 2 concludes first, followed by 1, 3 and 4. During the time span of 10:53:29-10:54:22, the employee is thus taking part in three interactions simultaneously (see Figure 4). In terms of subject matter, the interactions in Cluster 2 concern questions about employment as an adult office clerk, rights during maternity leave, and a desire to be contacted by telephone. 
It transpires that Interactions 2 and 4 are initiated by one and the same union member. Since there is a technical problem in Interaction 2, the member starts up a new chat interaction (Interaction 4)

The first interaction (Interaction F) is initiated by a member who asks about salary levels when signing an office clerk contract. In an attempt to give as full a context-dependent picture as possible regarding what happens with those taking part up until the parallel time span, Interaction $\mathrm{F}$ is reproduced in its entirety.

\section{Interaction $F$}

Turn Point in time

Interaction

$1 \quad 10: 46: 10$

A $-\mathrm{Hi}$, welcome to Krifa, how can I help you?

$2 \quad 10: 47: 40$

I wrote to you a few days ago about a job as an office clerk. I'm doing an HGS course at the moment and have got a job as an office clerk at a sixth form college (a privately owned one). And before I sign a contract (which l'll get next week), I'd like to know what salary I can ask for as someone who's 32 years old.

$3 \quad 10: 48: 08 \quad M$ and by the way whether I get paid holidays or how that works

We'll have to get one of our union advisers to answer you on that.

I can get one to phone you, or you can choose to ring yourself whenever it suits you It's completely up to you.

$7 \quad 10: 49: 14 \quad M$

ok. You must have my e-mail lying there somewhere - can't you just get them to send an e-mail? I'm busy doing exams this week and am a bit pushed :)

$8 \quad 10: 49: 57 \quad$ E $\quad$ Yes, I can do that. But you'll have to be prepared for us having to write back and forth a few times. It's got to do with such things as agreements. that's fine by me. Thanks for your help.

$10 \quad 10: 50: 40 \quad E$

I'll get a colleague to write to you. I need the following information: What's the name of the firm where you're working What's your position? Is there an agreement that applies at your workplace? When did you start your job?

$11 \quad 10: 51: 56 \quad$ E $\quad$ Sorry that some of the questions don't exactly fit your situation :)

$12 \quad 10: 52: 37 \quad E \quad$ We just need to know a bit about your employment and the agreement to be able to answer specifically. 
That's fine.the college [sic] is [name] in [town]. My position is office clerk, specialising in administration. I don't know about the agreement, I assume it's HK. I started last Friday.

--- start of the parallel time span

$\begin{array}{llll}14 & 10: 53: 52 & \text { E } & \text { We'll write to [e-mail address], ok? } \\ 15 & 10: 54: 04 & \text { M } & \text { that's right:) } \\ 16 & 10: 54: 19 & \text { E } & \text { Fine. Best of luck. } \\ 17 & 10: 54: 22: & \text { E } & \text { [End of call] }\end{array}$

$A$ is automatically generated. $M$ is the trade union member. $E$ is the employee.

As can be seen, the first interaction in Cluster 2 (Interaction F) has been going on for 7:19 prior to the parallel time span. During the parallel time span, the employee takes a turn to ask a question and concludes the question with "[...] ok?" to emphasise that there is a question that needs answering (turn-taking Rule 1a). The member supplies an answer in the next turn, which takes place only 12 seconds later. The employee acknowledges the answer ("Fine" (turn-taking Rule 1b)) 15 seconds later, after which the chat ends.

The second interaction (Interaction G) in Cluster 2 concerns contact with the trade union and is initiated at 10:51:34. It has thus been going on for 1:55 prior to the parallel time span. Up until the parallel time span, Interaction $\mathrm{G}$ goes as follows (included here because it is the only content in the interaction):

\begin{tabular}{|c|c|c|c|}
\hline Turn & Point in time & & Interaction \\
\hline 1 & $10: 51: 34$ & $E$ & [Contacts server: Accepts call] \\
\hline 2 & $10: 51: 35$ & $E$ & [Digital image started] \\
\hline 3 & $10: 52: 38$ & M & $\begin{array}{l}\text { I sent a message last Tuesday morning [sic] and was prom- } \\
\text { ised that someone would phone me on Tuesday or Wednes- } \\
\text { day }\end{array}$ \\
\hline 4 & $10: 52: 46$ & M & I haven't heard anything yet \\
\hline
\end{tabular}

The share of Interaction G during the parallel time span, when isolated, looks like this:

$\begin{array}{llll}\text { Turn } & \text { Point in time } & \text { Interaction } \\ 5 & 10: 53: 06 \quad E & \text { [End of call] }\end{array}$

$M$ is the trade union member. $E$ is the employee.

The chat interaction does not begin with the automatically generated "- $\mathrm{Hi}$, welcome to Krifa, how can I help you?", but the member chats two turns at an interval of eight seconds. 
The employee does not contribute any chat input in this interaction. It is not known if the member lost patience and broke off the chat interaction, if a computer problem arose, or if there was another reason for the employee not participating. In any event, this is a chat interaction without any content on the part of the employee.

The third interaction (Interaction $\mathrm{H}$ ) in Cluster 2 concerns maternity leave.

When isolated, Interaction H's share during the parallel time span looks like this:

\begin{tabular}{|c|c|c|c|}
\hline Turn & Point in time & & Interaction \\
\hline 1 & 10:53:05 & M & $\begin{array}{l}\text { I work for the local authority and am [sic] entitled to eight } \\
\text { weeks' prenatal maternity leave }[\text { sic]... For me, that means } 30 \\
\text { November. }\end{array}$ \\
\hline 2 & $10: 53: 33$ & M & $\begin{array}{l}\text { since the end of September I have had partial sick leave - } 28 \\
\text { hours. }\end{array}$ \\
\hline 3 & $10: 53: 59$ & M & $\begin{array}{l}\text { have now been told [sic] that because of this partial sick } \\
\text { leave I'm only entitled to } 4 \text { weeks' prenatal maternity leave }\end{array}$ \\
\hline 4 & $10: 54: 09$ & M & how is that possible? \\
\hline 5 & $10: 55: 02$ & $\mathrm{E}$ & I'll need a union adviser to examine that and advise you. \\
\hline 6 & $10: 55: 11$ & $\mathrm{E}$ & Can we phone you in the course of the day? \\
\hline
\end{tabular}

$M$ is the trade union member. $E$ is the employee.

Interaction $\mathrm{H}$ has been going on for 1:22 prior to the parallel time span. Something that is not evident in the parallel time span but that significantly affects the content during the parallel time span and is thus mentioned here is that, seconds before the parallel time span begins, the employee takes part in the chat with a capitalised "YES?", which demonstrates that it is time for something to happen in the interaction (a prodder). It is, then, not the case that the employee chooses to remain in a waiting position. The member takes four consecutive turns (turn-taking Rule 1b) in order to pose her question. The first three of these turns provide background information about the member's situation, while the fourth turn deals exclusively with the question. The employee replies by saying that a union adviser will have to answer this. Nine seconds later, the employee asks directly if the member can be contacted by telephone during the day (turn-taking Rule 1b). This hands over the request for action to the member.

The fourth interaction (Interaction I) in Cluster 2 begins with the parallel time span itself and is thus an independent chat interaction that is at the same time an extension of Interaction $\mathrm{G}$ in the same cluster. Interaction l's share during the parallel time span looks like this: 


$\begin{array}{llll}\text { Turn } & \text { Point in time } & \text { Interaction } \\ 1 & 10: 53: 29 & \text { E } & \text { hi again. } \\ 2 & 10: 53: 31 & \text { E } & \text { You disappeared. } \\ 3 & 10: 53: 35 & \text { M } & \text { hi } \\ 4 & 10: 53: 40 & \text { M } & \text { did you get my message? } \\ 5 & 10: 54: 01 & \text { E } & \text { No, I didn't manage to read it. }\end{array}$

$M$ is the trade union member. $E$ is the employee.

Here too, the interaction does not begin with an automatically generated utterance but with two turns from the employee. To accommodate the member, the employee takes the speaking turn himself (turn-taking Rule 1b) since they lost contact with one another in Interaction $G$. The union member accepts the request for action from the first part of the adjacency pair (hi again-hi), then asks a question that shifts the turn back to the employee (turn-taking Rule 1b). The employee answers in the negative 21 seconds later.

\section{Cluster 2: Summary}

The following is characteristic of turn-taking during the parallel time span in this cluster:

- The member expresses a desire and prods for this despite the lack of a welcome greeting from Krifa - takes over the speaking turn (turn-taking Rule 1b).

- The employee asks questions and looks for acceptance (turn-taking Rule 1a) and acknowledges, asks questions directly and indirectly, and provides background information (turn-taking Rule 1b).

- The interval between turn-taking ranges from nine seconds to 1:03. Silence comes from the employee when he refers to a union adviser $(H$, Turns 4 and 5$)$ and from the member at the beginning of the interaction ( $G$, Turns 2 and 3 ).

There are adjacency pairs, both automatically and personally generated. There are no phantom adjacency pairs during the parallel time span.

The combined parallel interaction pattern in Cluster 2 looks as follows. (This is my construction, to clarify the sequence of turns. It does appear this way to the employee):

\begin{tabular}{|c|c|c|c|}
\hline Turn & Point in time & & Interaction \\
\hline $1(\mathrm{H} 1)$ & $10: 53: 05$ & $M$ & $\begin{array}{l}\text { I work for the local authority and am entitled to eight weeks' } \\
\text { prenatal maternity leave [sic]... For me, that means } 30 \\
\text { November. }\end{array}$ \\
\hline $2(\mathrm{G} 1)$ & $10: 53: 06$ & $E$ & [Call ended] \\
\hline $3(I 1)$ & $10: 53: 29$ & $E$ & hi again. \\
\hline $4(12)$ & $10: 53: 31$ & $E$ & You disappeared. \\
\hline
\end{tabular}




\begin{tabular}{|c|c|c|c|}
\hline $5(\mathrm{H} 2)$ & $10: 53: 33$ & $M$ & $\begin{array}{l}\text { since the end of September I have had partial sick leave }-28 \\
\text { hours. }\end{array}$ \\
\hline $6(13)$ & $10: 53: 35$ & $M$ & hi \\
\hline $7(14)$ & $10: 53: 40$ & $M$ & did you get my message? \\
\hline $8(\mathrm{~F} 1)$ & $10: 53: 52$ & $\mathrm{E}$ & We'll write to [e-mail address], ok? \\
\hline $9(\mathrm{H} 3)$ & $10: 53: 59$ & $M$ & $\begin{array}{l}\text { have now been told [sic] that because of this partial sick } \\
\text { leave I'm only entitled to } 4 \text { weeks' prenatal maternity leave }\end{array}$ \\
\hline $10(15)$ & $10: 54: 01$ & $\mathrm{E}$ & No, I didn't manage to read it \\
\hline $11(\mathrm{~F} 2)$ & $10: 54: 04$ & $M$ & that's right:) \\
\hline $12(\mathrm{H} 4)$ & $10: 54: 09$ & $M$ & how is that possible? \\
\hline $13(\mathrm{~F} 3)$ & $10: 54: 19$ & $\mathrm{E}$ & Fine. The best of luck. \\
\hline $14(F 4)$ & 10:54:22: & $\mathrm{E}$ & [The call ended] \\
\hline $15(\mathrm{H} 5)$ & $10: 55: 02$ & $\mathrm{E}$ & I'll need a union adviser to examine that and advise you. \\
\hline $16(H 6)$ & $10: 55: 11$ & $\mathrm{E}$ & Can we phone you in the course of the day? \\
\hline
\end{tabular}

Figure 5: Cluster 2: The parallel time span from the employee's perspective.

$M$ is the trade union member. $E$ is the employee.

Red $=$ Interaction $\mathrm{F}$

Green = Interaction G

Blue = Interaction $\mathrm{H}$

Brown = Interaction I

The parallel time span (Figure 5) lasts 0:53 and contains four interactions consisting of 16 turns (the individual interactions last from one to six turns). During this time span, it could become especially complicated for the employee to keep track of the many elements of conversation since the individual relationships to the preceding turn potentially lead to one of four chat interactions taking place. One of the four interactions $(\mathrm{G})$, however, concludes early during the parallel time span (Turn 2) and, as can be seen, the employee allows Interaction $\mathrm{F}$ to go almost two minutes without taking a turn. Not until the union member uses his fourth turn to directly ask "how is that possible?" and waits for a reply does the employee take two turns. This may be due to the fact that the employee is busy taking part in Interaction I (Turns 3, 4, 6, and 7). Interaction I is a continuation of Interaction G, but as can be seen (Turn 10), the employee does not have the time to get his bearings in that interaction before the call ends (Turn 2). The employee does, however, recognise the sender status of the insurance member, since he writes "hi again" as his first turn in the new interaction (Turn 3).

In Turns 3 and 4 as well as Turns 15 and 16 multiple turns occur, with the employee taking consecutive turns. These do not represent turn-taker shifts but merely turn shifts. In Cluster 2 , there is a turn-taker shift by the employee where the relationship to the previous interaction refers to the same local chat interaction. The employee focuses both on the previous 
turn of the individual chat interaction and on the subsequent turn since on several occasions he chooses to contribute with consecutive turns in the same interaction (Interactions $\mathrm{F}, \mathrm{H}$, and I) but also chooses not to take part (Interaction $\mathrm{H}$ ) for so long that the member prods him after 1:04 with the turn "how is that possible?", producing a new response point.

As in Cluster 1, the employee spends the longest time (= pause) in Cluster 2 to supply the turn units in cases of a reference to a more complex future sequence. This results in a 40-second break between the employee's Turns 14 and 15 during the parallel time span. It is here that the employee points out to the union member that "[...] I'll need a union adviser to examine that and advise you." The employee also has extremely short intervals (pauses) between turns (Turns 4 and 16) of two and nine seconds respectively. There is one smiley in the cluster, contributed by the union member in Turn 11's "That's right :)". The employee does not use any smileys in this cluster.

The employee takes nine out of the 16 turns. As in Cluster 1, the tone is friendly and pleasant. The employee's utterances "hi again”, "We'll write to [e-mail address], ok?", "No, I didn't manage to read it", "Fine. The best of luck" as well as the union members' utterances of "hi", "did you get my message", "that's right :)" paint a picture of an informal conversation in which all of those involved feel at ease. The inclusive "we" in "we'll write to" on the part of the employee and the personal "du" [informal form of the English-language 'you'] from the union member underscore the cooperation and sense of a shared venture between participants.

These are no signs of misunderstandings, which might have arisen from the number of interactions in which the employee is taking part. Only the time-related restriction is mentioned as a hindrance by the employee when he writes "No, I didn't manage to read it". The employee does not compensate for the absence of feedback signals but lets the silence speak for itself.

\section{Conclusion}

This study has analysed authentic chat interactions between an employee and a number of union members in closed forums, focusing in particular on the time span in which the employee is engaged in parallel chats with more than one member at a time (many oneto-one interactions). In the analysed chat clusters, the parallel time span varies from almost one minute to nearly three minutes, containing three and four interactions respectively. There are 13 and 16 turns during the parallel time spans in these interactions respectively.

During parallel time span, when an employee chats with several members simultaneously, turn-taking is seen as a variant of the turn-taking pattern we know from oral conversation (multiparty interaction). When the employee chats with several members simultaneously, an extended complexity potentially arises in relation to turn-taking coordination at the Transition Relevance Places (TRPs). Analysis of the material, however, revealed no coherence problems or other signs of confusion or misunderstanding during the parallel time spans. 
One strategic response to the increased theoretical complexity seems to be silence (pause). In the first cluster, the employee does not, for example, participate in Interaction C (automatically generated speaking turn in Turn 1). At the same time, multiple turns are seen in Interaction B, where the employee takes three consecutive turns (B3, B4 and B5).

During the parallel time span, consisting of the three to four ongoing interactions, the employee can choose between numerous TRPs without the other participants in the interactions being able to do the same since the members only take part in one Krifa chat interaction. This means that the employee is the only one who can choose between the turn-taking rules within all of the interactions that are taking place. The following turntaking pattern emerges: The employee answers the member's question ( $\mathrm{x}$ ), after which the employee in the subsequent turn elaborates on his answer $(y)$, after which the employee produces one part of an adjacency pair $(z)$. In the analysed material, there are no turns from the member between $(x)$ and $(y)$, whereas turns from the member may occur between $(y)$ and $(\mathrm{z})$. This pattern may be regarded as a placeholder for a chat interaction pattern that could potentially be incorporated into practice. The employee chooses, then, to contribute with a string of consecutive short turns (short multiple turns), often directly followed by further turn units. The adopted turn pattern could be viewed as a way in which the employee can manage the three or four interactions in which he is simultaneously taking part. Furthermore, the employee chooses to use parts of adjacency pairs in order to oblige the member and to create the impression of an active, service-minded listener.

Unlike in group interactions, in the analysed chat interactions, it is exclusively the employee who has these possibilities in the professional context. This possibility potentially lends the examined chat interactions a further level of asymmetry when compared with one-to-one analyses in which the expert is not analysed on the basis of the total quantity of chat interactions. In other words, the employee is the expert, and he is busily involved in many interactions over and above the one in which the member is personally taking part. This activity is, however, invisible to the members. Compared with oral institutional one-to-one conversation, oral group interactions, one-to-one chat interactions, and group chat interactions, this aspect (many one-to-one interactions) is something new. Unlike, for example, teacher-pupil interactions (work), we are here dealing with closed forums in which only one of the parties is able to follow all of the content.

In both clusters, the employee shows the same level of activity in two of the cluster's interactions ( $A$ and $B$ in Cluster 1; F and I in Cluster 2), whereas a third and a fourth interaction are only briefly given priority by the employee with very short active participation or are ignored, even though the member is waiting in the chat.

Apart from questions and adjacency pairs, other prominent elements are not observable. Only once are dots used to indicate hesitation (member), and smileys are only twice part of a turn unit (once from the employee and once from a member).

The employee orientates himself both to the interaction taking place and to future interaction but is also obliged to allow interaction to run on without making a contribu- 
tion for what must seem like an eternity in a chat context. The interesting thing is, then, that - unlike in other studies (Grønning, 2010) - the member does not react to this by, for example, prodding for an answer or demonstrating impatience in some other way. It seems to pay off to orientate oneself directly in relationship to the next chat participant, as is exemplified in Interaction F, where the employee's "[...] ok?" produces an immediate response from the member.

The employee is basically the expert to which the union members address themselves. Even though the employee and the members do not know one another and cannot see, hear, or touch one another, it is possible to sense an informal, pleasant tone, one in which both employee and union members - with the aid of such informal discourse markers as "just", "well", "then", "simply" and "ok" - create an interaction in which those involved feel at ease. This takes place despite the fast external tempo to which these chat interactions are subject and despite the technical difficulties that can, as occurs here for instance, cause an ongoing interaction to be lost.

The truly distinctive aspects of the chat interactions analysed in this study are that they are carried out as many one-to-one interactions between one party and several parties who have never met one another and that the interactions also contain a high degree of expectation regarding problem solving. When it potentially becomes complicated for the employee from the point of view of time and content to take part in several interactions simultaneously, the solution is silence and reference to a further expert (union adviser), solutions to which the members do not respond in an explicitly negative manner. As has been seen in other external chat interactions (Grønning, 2010), the employee does not compensate for the lack of feedback signals by meta-communicating during the interaction. The weakness of this study is that we are unable to know what else, if anything, the participants may have been doing while they were chatting.

By introducing external chatting, the workplace is opening up yet another medium for relationships between employees and customers (in this case, union members) as a supplement to telephone calls and e-mails. It transpires that chatting is closely linked to these two other forms of communication, to which there are often explicit references in the chat interactions (for instance, "But l'll get someone to phone [...]" and "We'll write to [e-mail address], ok?").

The basically asymmetrical relationship between employee and union member (customer) is challenged by the chat interactions, in which questions arise that the employee is unable to answer. Whereas it is possible to redirect a customer to someone else during a telephone conversation and whereas e-mail interactions can simply be forwarded to the right experts for the correct answers, it is necessary in chat interactions to refer to union advisers, who will then make contact. As far as the basically asymmetrical nature of the chat interaction is concerned, one can sense here a further level, so that there now appear to be three levels: the union member (customer), the employee (expert), and the union adviser (higher-level expert). This raises the question of to what extent these references to a higher- 
level expert and the complexity resulting from being unable to immediately answer a question may be counterproductive. The Krifa material shows that members do not explicitly react in a negative manner to this chat interaction. Further studies (for instance, interviews with members) are necessary to clarify this aspect in more detail.

\section{Notes}

1. The Sacks, Schegloff, \& Jefferson article was published in 1974 but was reprinted in Schenkein (Ed.), 1978.

2. A turn is: "[...] a real time, joint construction of the participants of a conversation" (Tanaka, 1999, p. 29).

\section{References}

Asmuss, B. \& Steensig, J. (Eds.) (2003). Samtalen på arbejde - konversationsanalyse og kompetenceudvikling. Frederiksberg: Samfundslitteratur.

Drew, P. \& Heritage, J. (Eds.) (1992). Talk at Work: Interaction in Institutional Settings. Cambridge, UK: Cambridge University Press.

Garcia, A.C. \& Jacobs, J.B. (1999). The eyes of the beholder: understanding the turn-taking system in quasisynchronous computer-mediated communication. Research on Language \& Social Interaction, 32(4), 337-367.

Grinter, R.E. \& Palen, L. (2002). Instant messaging in teen life. CHI Letters, 4(3), 21-30.

Grønning, A. (2010). Chat interaction in public and commercial domains. In K. Drotner \& K.C. Schrøder (Eds.). Digital Content Creation. New York: Peter Lang.

Herring, S.C. (1996). Computer-Mediated Communication: Linguistic, Social and Cross-Cultural Perspectives. Amsterdam: Benjamins.

Hougaard, T.T. (2004). Narmest en leg. En undersøgelse af sprog og interkation i dansk webchat. PhD thesis for Aarhus University.

Isaacs, E., Walendowski, A., Whittaker, S., Schiano, D.J. \& Kamm, C. (2002). The character, functions, and styles of instant messaging in the workplace. Proceedings of the 2002 ACM conference on Computer supported cooperative work, 11-20. New York, USA.

Krifa website. Consulted on 29.08.2011. www.krifa.dk.

Lenhart, A., Rainie, L., \& Lewis, O. (2001). Teenage Life Online: The Rise of the Instant Message Generation and the Internet's Impact on Friendships and Family Relationships. Pew Internet and American Life Project.

Nielsen, M.F., Steensig, J., \& Wagner, J. (2006). Konversationsanalyse i Danmark, NyS (Nydanske Studier), Sprogvidenskabelige forskningstraditioner, 34-35, 182-216.

Nielsen, M.F. \& Nielsen, S.B. (2005). Samtaleanalyse. Frederiksberg: Samfundslitteratur.

O'Neill, J. \& Martin, D. (2003). Text chat in action. Proceedings of Group 2003 Conference. Sanibel Island, USA.

Sacks, H., Schegloff, E.A., \& Jefferson, G. (1974). A simplest systematics for the organisation of turn-taking for conversation. Language, 50(4), 696-735. (Reprinted in Schenkein (Ed.) 1978, 7-55).

Schenkein, J. (Ed.) (1978). Studies in the Organization of Conversational Interaction. New York, San Francisco, \& London: Academic Press.

Smith, M., Cadiz, J. \& Burkhalter, B. (2000). Conversation Trees and Threaded Chats. Proceedings of the ACM 2000 Conference on Computer-Supported Cooperative Work, 97-105. Philadelphia, USA. 
Article: Structure, complexity and cooperation in parallel external chat interactions

Steensig, J. (2001). Sprog i virkeligheden. Bidrag til en interaktionel lingvistik. Aarhus: Aarhus Universitetsforlag.

Tanaka, H. (1999). Turn-Taking in Japanese Conversation: A Study in Grammar and Interaction. Amsterdam \& Philadelphia: John Benjamin's Publishing Company.

Viegas, F. \& Donath, J. (1999). Chat Circles. Proceedings of CHI 99, 9-16. Pittsburgh, USA.

Anette Grønning

Associate Professor, PhD

Institute for the Study of Culture - Media Studies

University of Southern Denmark

ahg@sdu.dk 